\title{
Analisa Faktor-Faktor Perlambatan Arus Lalu Lintas Di Ruas Jalan Sutorejo Dan Jalan Krajan Kabupaten Lumajang Berbasis Nilai Volume Kendaraan
}

\author{
Hendrata Wibisana, Ibnu Sholichin, Eric Ardianto \\ Program Studi Teknik Sipil, UPN Veteran Jawa Timur \\ Email : hendrata2008@gmail.com
}

\begin{abstract}
The slowing of traffic flows, especially in arterial roads which has connecting two important administrative areas such as Lumajang district with Jember district, will have a disadvantage, especially in terms of economic losses and the prolonged of air pollution. This study aims to find out which factors of the traffic flow characteristics most dominant in providing the factor of slowing down the movement of traffic flow along the arterial road. The selected road segment like Sutorejo highway and Krajan highway in district of Lumajang, by using multi variable regression analysis it's has be done the determination of the dominant factor who cause the slowdown of the traffic. In addition, with the analysis of Greenshield method would be produced the maximum speed of the movement of vehicles that cross the highway. From the calculation the results show coefficient value for motorcycles is $\mathbf{0 . 0 0 4 5}$, it' $\mathbf{s}$ has a dominant value compared to the light vehicles and heavy vehicles, while the mean square error is $8.2 \times 10^{-8}$ for the road Sutorejo, just for Krajan road the coefficient value for vehicle was 0.0047 , the most dominant value with a root mean square value 0,0011 . The maximum speed obtained for the Sutorejo road is $86 \mathrm{~km} / \mathrm{h}$ and $1162 \mathrm{pcu} / \mathrm{km}$ for density of road. The conclusion taken for Sutorejo road and Karajan road that heavy vehicle is the dominant factor in increasing the value of $D S$ that resulted in the slowing of traffic flow.
\end{abstract}

Keywords: traffic flow, degree of saturation, free flow speed, traffic congestion.

\begin{abstract}
Abstrak
Perlambatan arus lalu lintas terutama di jalan arteri yang menghubungkan 2 daerah administrasi yang penting seperti kabupaten Lumajang dengan kabupaten Jember akan memberikan dampak yang kurang menguntungkan terutama ditinjau dari aspek kerugian ekonomi serta timbulnya polusi udara yang berkepanjangan. Penelitian ini bertujuan untuk mencari faktor manakah dari karakteristik arus lalu lintas yang paling dominan dalam memberikan faktor perlambatan terhadap pergerakan arus lalu lintas sepanjang ruas jalan arteri. Ruas jalan yang dipilih adalah jalan raya Sutorejo dan jalan raya Krajan di kabupaten lumajang, dan dengan menggunakan analisa regresi multi variabel dapat dilakukan penentuan faktor dominan penyebab perlambatan tersebut. Disamping itu dengan analisa Greenshield dihasilkan kecepatan maksimum dari pergerakan kendaraan yang melintas di ruas jalan raya tersebut. Dari hasil perhitungan didapatkan nilai koefisien untuk sepeda motor sebesar 0,0045, memiliki nilai yang dominan dibandingkan dengan kendaraan ringan dan kendaraan berat, sedangkan kuadrat rata-rata kesalahan diperoleh $8,2 \times 10^{-8}$ untuk jalan Sutorejo, untuk jalan Krajan didapatkan nilai koefisien untuk kendaraan berat sebesar 0,0047 , nilai yang paling dominan dengan nilai kuadrat rata-rata kesalahan 0,0011. Kecepatan maksimum yang diperoleh untuk jalan Sutorejo adalah $86 \mathrm{~km} / \mathrm{jam}$ dan untuk kepadatan jalan saat jenuh $1162 \mathrm{smp} / \mathrm{km}$. Kesimpulan yang diambil untuk ruas jalan Sutorejo dan jalan Krajan bahwa kendaraan berat adalah faktor yang dominan dalam memperbesar nilai DS yang berakibat kepada terjadinya perlambatan arus lalu lintas.
\end{abstract}

Kata kunci: Arus lalu lintas, derajad kejenuhan, kecepatan arus bebas, kepadatan lalu lintas 


\section{Pendahuluan}

Kepadatan arus lalu lintas merupakan suatu fenomena yang sering dijumpai dalam ruas jalan yang ramai atau merupakan jalan utama dari mobilitas berbagai jenis kendaraan dari satu daerah menuju ke daerah yang lain (Webster, 1966). Penelitian mengenai arus lalu lintas dan kepadatan jalan raya sudah banyak yang meneliti ditinjau dari lokasi dan metode yang digunakan (Yang, 2017). Kepadatan ruas jalan menarik untuk diteliti karena kepadatan identik dengan perlambatan arus lalu lintas dan juga dampak ekonomi yang ditimbulkan (Ahmane, 2013; Truong, 2017). Dan sebagai akibat samping dari kepadatan tersebut dapat menimbulkan polusi udara yang tidak dikehendaki (Coelho, 2005; Olia, 2014). Untuk jalan di pertigaan ataupun perempatan yang memiliki volume yang tinggi pengaturan traffic light dan arah laju kendaraan memiliki model tersendiri untuk pergerakan arus lalu lintasnya (Chou, 2012; Gartner, 1983; Goodal, 2013; Tiaprasert, 2015). Sebagai ruas jalan yang dikategorikan sebagai ruas jalan utama maka jalan raya Sutorejo dan jalan Raya Krajan memiliki mobilitas kendaraan yang cukup besar untuk kondisi kabupaten Lumajang, dimana pergerakan kendaraan dari kabupaten Lumajang yang bergerak menuju kabupaten Jember dihubungkan dengan ruas jalan tersebut. Penelitian ini bertujuan untuk mencari faktor-faktor yang paling dominan dari berbagai jenis kendaraan yang melintas di ruas jalan tersebut, dimana jenis kendaraan yang pilih berdasarkan aturan dari manual kapasitas jalan Indonesia (MKJI ) yaitu jenis kendaraan roda dua (MC), kendaraan ringan (LV) serta kendaraan berat (HV). Penelitian yang banyak dilakukan adalah mengukur volume total dari kendaraan untuk kemudian dianalisa situasi, derajat kejenuhan (DS) dan karakteristik jalannya, sedangkan pendekatan yang dilakukan pada penelitian ini adalah mencari jenis kendaraan manakah yang paling dominan dalam memperbesar nilai DS dan seberapa besar nilai faktor yang ditimbulkan, disamping itu hendak dilihat berapakah kecepatan maksimum dari kendaraan yang melintas yang masih dapat bergerak akibat perlambatan yang terjadi pada ruas jalan tersebut.

\section{Metodologi}

Lokasi penelitian mengambil ruas jalan Raya Sutorejo dan ruas jalan Raya Krajan yang menghubungkan kabupaten Lumajang dengan kabupaten Jember, dapat dilihat pada Gambar.1

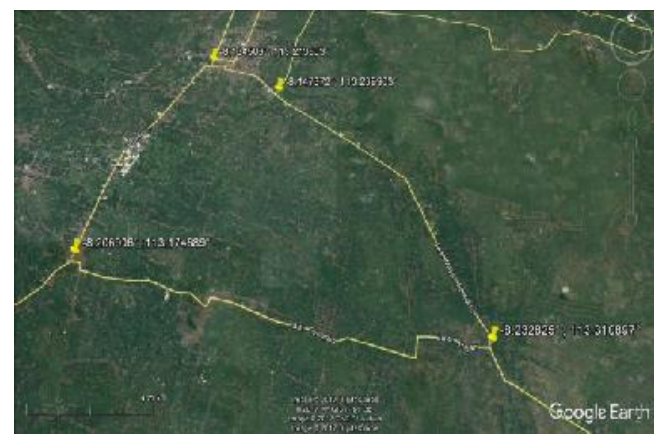

Gambar 1. Lokasi penelitian ruas jalan Sutorejo dan ruas jalan Krajan kabupaten Lumajang

Koordinat penelitian adalah $-8,206906^{\circ}$ Lintang Selatan dan $113,174689^{\circ}$ Bujur Timur saat memasuki jalan Sutorejo hi- 


\section{ISSN.1907-753X}

ngga mencapai $-8,232825^{\circ}$ Lintang Selatan dan $113,310897^{\circ}$ Bujur Timur sebagai akhir dari jalan Krajan.

Penelitian ini dilakukan pada ruas jalan Raya Sutorejo dan jalan Raya Krajan di kabupaten Lumajang pada tanggal 4 Pebruari 2017 dengan waktu penelitian jam 06.00 wib hingga jam 09.00 wib. Pencatatan volume kendaraan dilakukan terhadap masing-masing jenis kendaraan motor cycle (MC), kendaraan ringan (LV) dan kendaraan berat (HV) dalam satuan kendaraan per jam, setelah data diperoleh dilakukan konversi kedalam satuan smp/jam sesuai aturan dari manual kapasitas jalan Indonesia (MKJI) dan diperoleh nilai Volume total atau Q. Nilai derajad kejenuhan (DS) dihitung dari perbandingan total volume kendaraan seluruhnya terhadap nilai kapasitas jalan yang ada. Untuk perhitungan kapasitas jalan juga disesuaikan dengan aturan dari MKJI dan diperoleh nilai kapasitas jalan atau $\mathrm{C}$.

Untuk analisis faktor yang dominan maka data dari jenis kendaraan tetap dipertahankan tidak dijumlah total, dan masing-masing kolom dari nilai jumlah kendaraan dalam satuan smp/jam dihitung dengan analisa regresi berganda dengan program excel terhadap nilai derajat kejenuhan yang tertinggi dari jumlah data yang ada.

Untuk penentuan kecepatan maksimum dilakukan dengan menggunakan perhitungan model Greenshield dengan bentuk model persamaan:

$S=S_{f f}-\frac{S_{f f}}{D j} * D$
Dimana $S$ adalah kecepatan dalam $\mathrm{km} / \mathrm{jam}, \mathrm{D}$ adalah kepadatan kendaraan dalam smp/km, Sff adalah kecepatan arus bebas dalam $\mathrm{km} / \mathrm{jam}$ sedangkan $\mathrm{Dj}$ adalah kepadatan saat arus jenuh dalam satuan smp/km.

\section{Hasil dan Pembahasan}

Ruas Jalan Raya Sutorejo

Untuk perhitungan volume lalu lintas diperoleh data-data lapangan yang ditampilkan pada Tabel 1.

Tabel 1. Data lapangan volume kenda raan jalan Raya Sutorejo kabupaten Lumajang

\begin{tabular}{cccc}
\hline $\begin{array}{c}\text { MC } \\
\text { smp/jam }\end{array}$ & $\begin{array}{c}\text { LV } \\
\text { smp/jam }\end{array}$ & $\begin{array}{c}\text { HV } \\
\text { smp/jam }\end{array}$ & $\begin{array}{c}\text { Q } \\
\text { smp/jam }\end{array}$ \\
\hline 28 & 306 & 22 & 602 \\
24 & 267 & 32 & 464 \\
36 & 262 & 30 & 554 \\
40 & 268 & 28 & 584 \\
60 & 229 & 32 & 592 \\
52 & 203 & 40 & 484 \\
52 & 237 & 32 & 588 \\
60 & 212 & 36 & 620 \\
56 & 182 & 44 & 516 \\
88 & 130 & 48 & 612 \\
64 & 190 & 40 & 588 \\
60 & 142 & 52 & 640 \\
\hline
\end{tabular}

Keterangan : $\mathrm{MC}=$ sepeda motor; $\mathrm{LV}=$ kendaraan ringan ; $\mathrm{HV}=$ kendaraan berat ; $\mathrm{Q}=$ volume total kendaraan $(\mathrm{MC}+\mathrm{LV}+\mathrm{HV})$

Untuk perhitungan kapasitas jalan Sutorejo dilakukan sebagai berikut:

Perhitungan kapasitas jalan (MKJI, 1999)

$\mathrm{C}=\mathrm{C}_{0} \times \mathrm{F}_{\mathrm{CW}} \times \mathrm{F}_{\mathrm{CSP}} \times \mathrm{F}_{\mathrm{CSF}} \times \mathrm{F}_{\mathrm{CCS}}$

$\mathrm{C}=2900 \times 0,87 \times 1,00 \times 1,01 \times 1,00$

$\mathrm{C}=2548,23 \mathrm{Smp} / \mathrm{jam}$

$\mathrm{C}=2549$ Smp/jam (dibulatkan) 
Nilai kapasitas ini digunakan untuk menghitung derajat kejenuhan dengan rumus:

$D s=\frac{Q}{C}$

Dimana : Ds = derajat kejenuhan $; \mathrm{Q}=$ volume lalu lintas, $\mathrm{C}=$ kapasitas lalu lintas

Setelah nilai kapasitas diperoleh maka dilakukan perhitungan nilai derajat kejenuhan (DS) untuk jalan raya Sutorejo dan diperoleh hasil pada Tabel 2.

Tabel 2. Data nilai kapasitas dan DS jalan

\begin{tabular}{cccc}
\multicolumn{4}{c}{ raya Sutorejo } \\
\cline { 1 - 2 } No & $\begin{array}{c}\mathrm{Q}(\mathrm{smp} / \\
\text { jam })\end{array}$ & $\begin{array}{c}\mathrm{C} \\
(\mathrm{smp} / \\
\text { jam })\end{array}$ & $\mathrm{DS}=\mathrm{Q} / \mathrm{C}$ \\
\hline 1 & 602 & 2549 & 0,2362 \\
2 & 464 & 2549 & 0,1821 \\
3 & 554 & 2549 & 0,2174 \\
4 & 584 & 2549 & 0,2292 \\
5 & 592 & 2549 & 0,2323 \\
6 & 484 & 2549 & 0,1900 \\
7 & 588 & 2549 & 0,2308 \\
8 & 620 & 2549 & 0,2433 \\
9 & 516 & 2549 & 0,2025 \\
10 & 612 & 2549 & 0,2402 \\
11 & 588 & 2549 & 0,2308 \\
12 & 640 & 2549 & 0,2512 \\
\hline
\end{tabular}

Perhitungan untuk menentukan faktor dominan penyebab perlambatan arus lalu lintas dilakukan dengan regresi linier berganda dan diperoleh hasil model persamaan :

$y=0,00061 x 1+0,00058 \times 2+$ $0,0025 x 3$
Dimana $\mathrm{y}=$ nilai $\mathrm{DS}, ; \mathrm{x} 1=$ sepeda motor ; x2 = kendaraan ringan ; x3 = kendaraan berat

Nilai koefisien $\mathrm{R}^{2}=0,99$ dan nilai Mean square error sebesar $8,9 \times 10^{-8}$

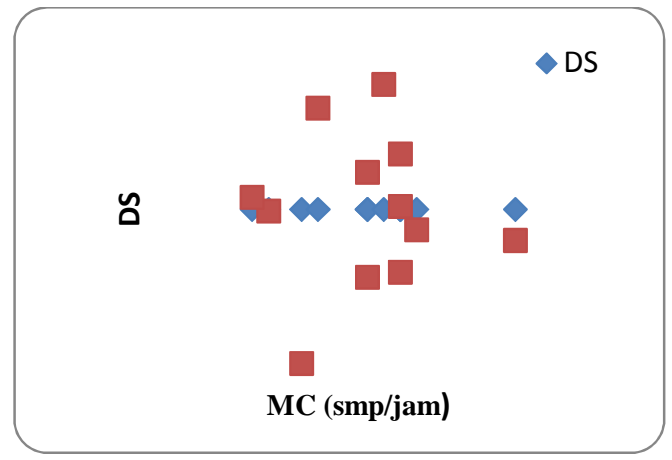

Gambar 1. Grafik perbandingan nilai DS lapangan dengan nilai Ds hitungan program untuk sepeda motor

Untuk gambaran hubungan volume dari jenis kendaraan terhadap nilai DS lapangan dan DS dugaan diperlihatkan pada Gambar 2. untuk tipe kendaraan MC, Gambar 3. untuk tipe kendaraan LV dan Gambar 4. untuk tipe kendaraan HV

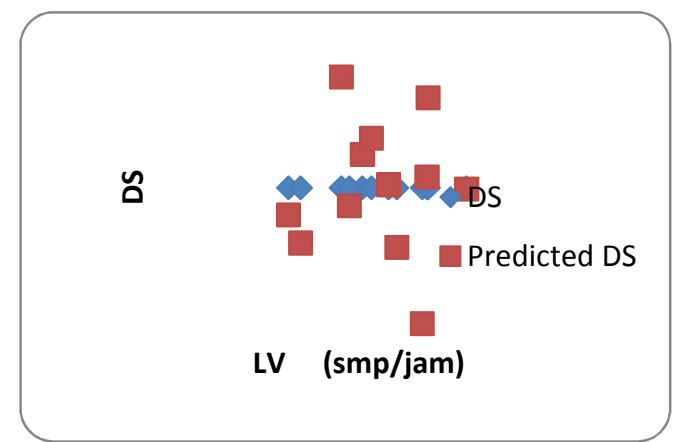

Gambar 2. Grafik perbandingan nilai Ds lapangan dengan nilai Ds hitungan program untuk kendaraan ringan (LV) 


\section{ISSN. 1907-753X}

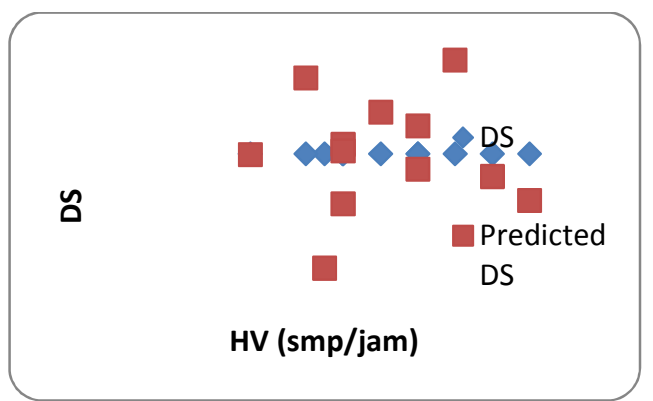

Gambar 3. Grafik perbandingan nilai Ds lapangan dengan nilai Ds hitungan program untuk kendaraan berat (HV)

Sedangkan Gambar 5 memperlihatkan sebaran nilai residu atau error dari hasil pengukuran regresi berganda terhadap volume kendaraan yang melintas pada ruas jalan Sutorejo.

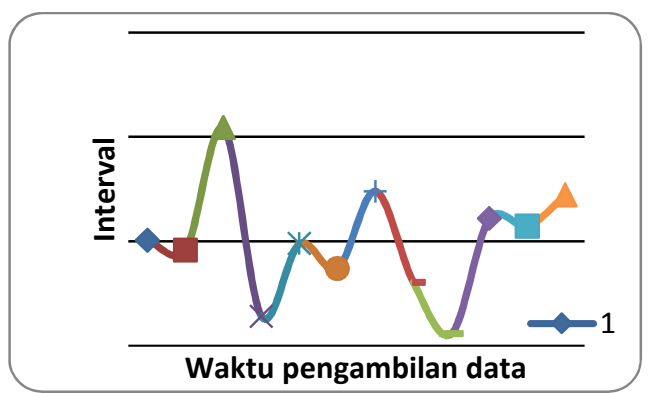

Gambar 4. Sebaran nilai residual terhadap waktu pengamatan di ruas jalan Sutorejo

Untuk perhitungan kecepatan arus bebas digunakan model Greenshield dan diperoleh hasil :

$$
y=86,0-0,074 \cdot x
$$

atau

$$
\begin{aligned}
& S=86,0-0,074 \cdot D \\
& S_{f f}=86 \mathrm{~km} / \mathrm{jam} \\
& D j=1162 \mathrm{smp} / \mathrm{km}
\end{aligned}
$$

Sehingga hasil akhir untuk ruas jalan Sutorejo memiliki kecepatan kendaraan pada kondisi arus bebas sebesar 86 $\mathrm{km} / \mathrm{jam}$ dan kepadatan kendaraan sebesar $1162 \mathrm{smp} / \mathrm{km}$

\section{Ruas Jalan Raya Krajan}

Untuk perhitungan volume lalu lintas lapangan di ruas jalan Krajan dapat dilihat pada Tabel 3 .

Data kapasitas jalan Krajan kemudian dihitung dengan menggunakan aturan MKJI 1999 dan diperoleh hasil sebagai berikut :

$$
\begin{aligned}
\mathrm{C} & =\mathrm{C}_{0} \times \mathrm{F}_{\mathrm{CW}} \times \mathrm{F}_{\mathrm{CSP}} \times \mathrm{F}_{\mathrm{CSF}} \times \mathrm{F}_{\mathrm{CCS}} \\
\mathrm{C} & =2900 \times 0,87 \times 1,00 \times 0,99 \times 1,00 \\
\mathrm{C} & =2497,77 \mathrm{Smp} / \mathrm{jam} \\
\mathrm{C} & =2498 \mathrm{Smp} / \mathrm{jam} \text { (dibulatkan) }
\end{aligned}
$$

Tabel 3. volume lalu lintas lapangan di ruas jalan Krajan.

\begin{tabular}{cccc}
\hline $\begin{array}{c}\text { MC } \\
(\text { smp/jam })\end{array}$ & $\begin{array}{c}\text { LV } \\
(\text { smp/jam })\end{array}$ & $\begin{array}{c}\text { HV } \\
(\text { smp/jam })\end{array}$ & $\begin{array}{c}\text { Q } \\
(\text { smp/jam })\end{array}$ \\
\hline 64 & 572 & 52 & 688 \\
76 & 580 & 52 & 708 \\
60 & 508 & 44 & 612 \\
48 & 608 & 56 & 712 \\
56 & 476 & 40 & 572 \\
56 & 524 & 36 & 616 \\
48 & 644 & 48 & 740 \\
44 & 500 & 32 & 576 \\
32 & 376 & 24 & 432 \\
16 & 384 & 12 & 412 \\
20 & 296 & 16 & 332 \\
32 & 364 & 12 & 408 \\
\hline
\end{tabular}

Keterangan : Q (volume total $)=\mathrm{MC}+$ $\mathrm{LV}+\mathrm{HV}$

Untuk nilai DS jalan Krajan ditampilkan pada Tabel 4. sebagai rasio perbandingan Volume lalu lintas terhadap kapasitasnya. 
Tabel 4. Data nilai kapasitas dan DS jalan

\begin{tabular}{ccc}
\multicolumn{2}{c}{ raya Krajan } & \\
\hline $\begin{array}{c}\mathrm{Q} \\
(\mathrm{smp} / \mathrm{jam})\end{array}$ & $\begin{array}{c}\mathrm{C} \\
(\mathrm{smp} / \mathrm{jam})\end{array}$ & $\mathrm{DS}$ \\
\hline & & \\
588 & 2498 & 0,235 \\
656 & 2498 & 0,263 \\
612 & 2498 & 0,245 \\
656 & 2498 & 0,263 \\
664 & 2498 & 0,266 \\
508 & 2498 & 0,203 \\
736 & 2498 & 0,295 \\
704 & 2498 & 0,282 \\
492 & 2498 & 0,197 \\
664 & 2498 & 0,266 \\
612 & 2498 & 0,245 \\
728 & 2498 & 0,291 \\
\hline
\end{tabular}

Perhitungan untuk menentukan faktor dominan penyebab perlambatan arus lalu lintas dilakukan dengan regresi linier berganda dan diperoleh hasil model persamaan:

$y=0,00097 x 1+0,00024 x 2+$ $0,0075 \times 3$

Dimana $\mathrm{y}=$ nilai $\mathrm{DS}, ; \mathrm{x} 1=$ sepeda motor ; $\mathrm{x} 2=$ kendaraan ringan $; \mathrm{x} 3=$ kendaraan berat

Nilai koefisien $\mathrm{R}^{2}=0,98$ dan nilai Mean square error sebesar 0,0011

Dan sebagai gambaran dari model persamaan 3 tersebut dapat dilihat pada Gambar 6 untuk hubungan MC terhadap nilai DS, Gambar 7 untuk hubungan LV terhadap nilai DS, Gambar 8 untuk hubungan HV terhadap nilai DS

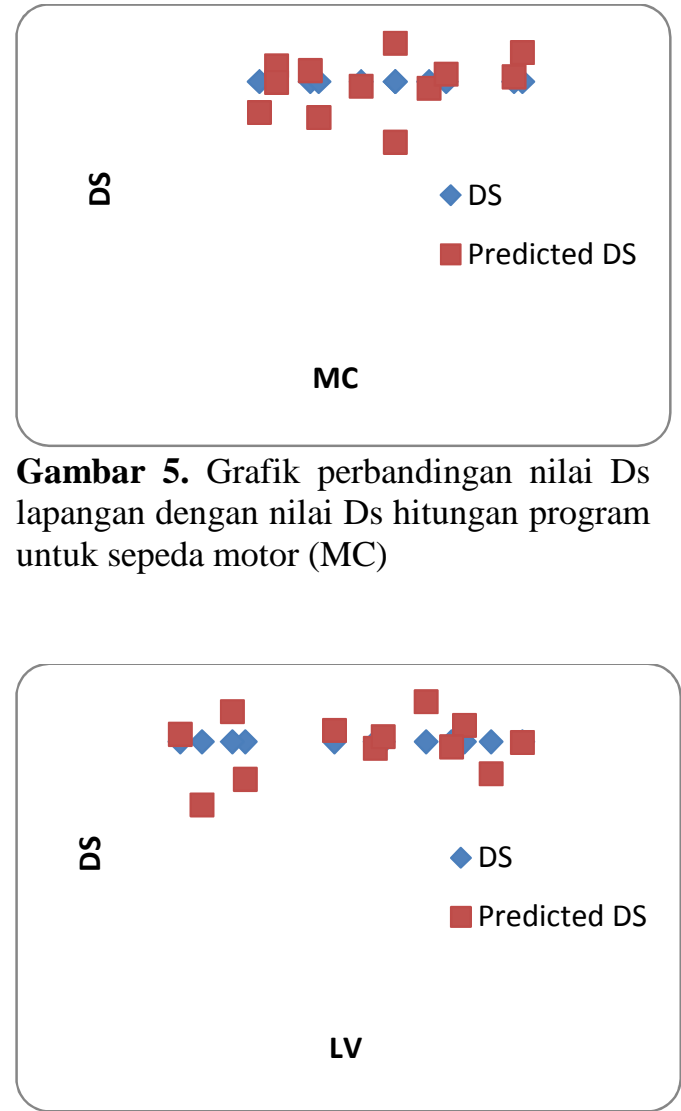

Gambar 6. Grafik perbandingan nilai Ds lapangan dengan nilai Ds hitungan program untuk kendaraan ringan (LV)

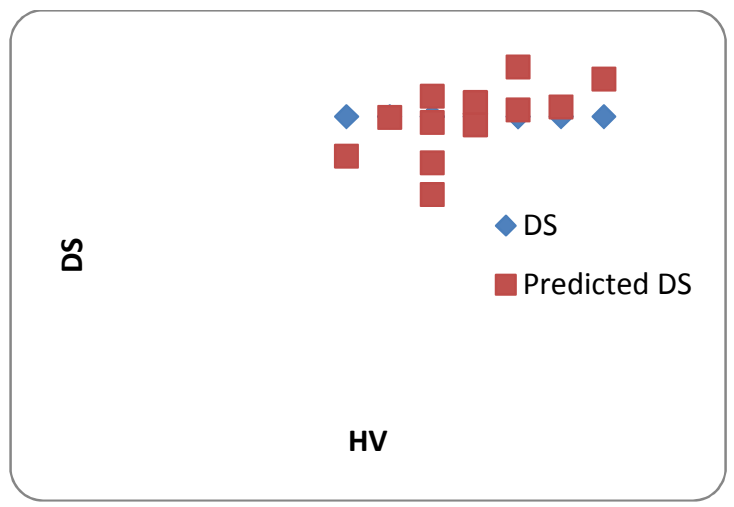

Gambar 7. Grafik perbandingan nilai Ds lapangan dengan nilai Ds hitungan program untuk kendaraan berat (HV) 


\section{ISSN. 1907-753X}

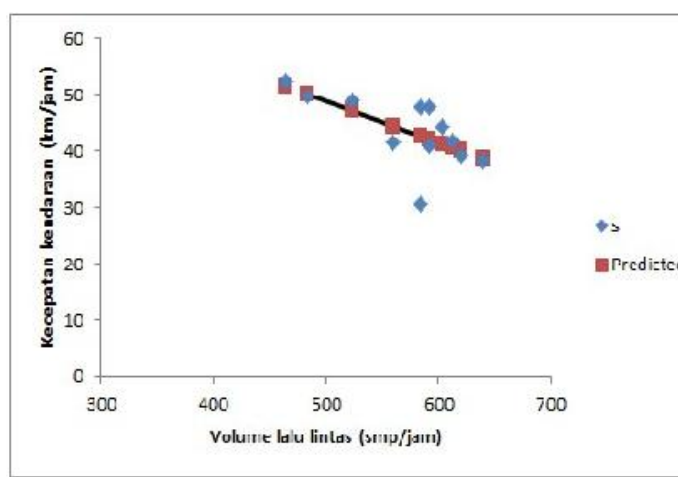

Gambar 8. Grafik hubungan kecepatan kendaraan dengan kecepatan hasil perhitungan model Greenshield

\section{Simpulan}

Dari perhitungan regresi multi variabel dapat dilihat bahwa kendaraan berat (HV) memiliki nilai yang dominan terhadap perlambatan arus lalu lintas baik yang terjadi di ruas jalan Sutorejo maupun pada ruas jalan Krajan di kabupaten Lumajang. Kecepatan kendaraan pada arus bebas yang dapat diprediksi adalah $86 \mathrm{~km} / \mathrm{jam}$ dengan nilai kepadatan saat arus jenuh sebesar $1162 \mathrm{smp} / \mathrm{km}$.

\section{Ucapan Terima kasih}

Penulis mengucapkan terima kasih kepada Program Studi Teknik Sipil yang sudah memberikan kesempatan penggunaan laboratorium komputer untuk perhitungan dan analisis hasil penelitian, serta kepada para mahasiswa yang sudah bersedia membantu sebagai tenaga surveyor lapangan

\section{Daftar Pustaka}

Ahmane, M.; et.al, 2013. Modeling and controlling an isolated urban intersection based on cooperative vehicles. Tramsp. Res. Part C Emerg. Technol., 28, 44-62.

Chou, L.D., et al, 2012. A passenger-based adaptive traffic signal control mechanism in Intelligent Trans portation Systems. In Proceedings of the International Conference on ITS Telecommunications, Taipei, Taiwan, 5-8 November.

Coelho, M.C. and Farias, T.L., 2005. Impact of speed control traffic signals on pollutant emissions. Transp. Res. Part D Transp. Environ. 10, 323-340.

Departemen Pekerjaan Umum, 1999. Manual Kapasitas Jalan Indonesia, Jakarta. MKJI.

Gartner, N.H. OPAC: 1983. A Demand Responsive Strategy for Traffic Signal Control; Transportation Research Record: Washington, DC, USA, No. 906; pp. 75-81.

Goodall, N.J, and Smith, B.L., 2013. Traffic Signal Control with Connected Vehicles. Transp. Res. Rec. J. Transp. Res. Board, 2381, 65-72.

Li, M. et.all, 2009. Traffic Energy and Emission Reductions at Signalized Intersections: A Study of the Benefits of Advanced Driver Information. Int. J. Intell. Transp. Syst. Res. 7, 2327-2332.

Olia, A., et al, 2014. Assessing the Potential Impacts of Connected Vehicles:Mobility,Environmental, and Safety Perspectives. J. Intell. Transp. Syst. Technol. Plan. Oper. 23, ix-xii.

Rachmad Basuki, Fiany Dara Novelita, Endah Tri Listiari, 2016. Kajian Bundaran Mulyosari Menjadi Simpang Bersinyal. Jurnal Aplikasi Teknik Sipil, Vol 14 No.1, Hal. 43-54. DOI: http://dx.doi.org/10.12962/j2 579-891X.v14i1.3047 
Tiaprasert, K. et.al, 2015. Queue Length Estimation Using Connected Vehicle Technology for Adaptive Signal Control. IEEE Trans. Intell. Transp. Syst. 16, 2129-2140.

Truong, L.T., et.al, 2017. Estimating the trip generation impacts of autonomous vehicles on car travel in Victoria,

Australia. Transportation, 1-14.

Webster, F.V. and Cobbe, B.M. 1966. Traffic Signals; Road Research Technical Paper No. 56; Her Majesty's Stationery Office: London, UK,; Volume 4, pp. 206207.

Yang, K. A. 2017. Reinforcement Learning Based Traffic Signal Control Algorithm in a Connected Vehicle Environment. In Proceedings of the 17th Swiss Transport Research Conference (STRC 2017), Ascona, Switzerland, 17-19, May. 